\title{
Management Control for Stimulating Different Types of Creativity: The Role of Budgets
}

\author{
Martine Cools \\ KU Leuven - Faculty of Business and Economics (FBE) \\ Kristof Stouthuysen
}

Vlerick Business School; KU Leuven

Alexandra G. H. L. Van den Abbeele

Katholieke Universiteit Leuven (K.U.Leuven)

August 1, 2011

AAA 2012 Management Accounting Section (MAS) Meeting Paper

\begin{abstract}
:
In this paper, we examine the role of budgets, as a central instrument within the management control system, in a creative context. In particular we investigate whether Simons' (199'8 1991, 1995) claim that stimulating creativity requires an interactive use of management controls, holds when differences in the kind of creativity are taken into account. We hereby distinguish between expected creativity (for open, self-discovered problems) versus responsive creativity (for closed, presented problems) (Unsworth, 2001). Based on a comparative study involving four creative organizations, we find indications that creative firms being mainly characterized by expected creativity use their budgets in a more interactive way. In creative firms in which responsive creativity is most important, the budgets are used in a rather diagnostic way. This study makes an important contribution to the management control literature by acknowledging that a diagnostic use of budgets does not per se stifle creativity. Instead, it is important to understand that the specific creative context might have implications for the way in which management control instruments are used to sustain the creative process.
\end{abstract}

Number of Pages in PDF File: 35

Keywords: expected creativity, responsive creativity, diagnostic and interactive budget use working papers series 